\title{
Ambiguous Words in Context: An Event-Related Potential Analysis of the Time Course of Meaning Activation
}

\author{
Cyma Van Petten and Marta Kutas
}

University of California, San Diego

\begin{abstract}
Words with a single spelling and pronunciation but at least two distinct meanings (homographs) were used to terminate sentences of moderate contextual constraint. Following each sentence, a target was presented which was either (1) related to the contextually biased meaning of the homograph, (2) related to the unbiased meaning, or (3) unrelated to either meaning. Across subjects, the stimulus onset asynchrony (SOA) between homograph and target was either short $(200 \mathrm{~ms})$ or long $(700 \mathrm{~ms})$. The naming latencies recorded in Experiment 1 revealed priming for both contextually appropriate and inappropriate related targets at the short SOA but for only the contextually appropriate targets at the long SOA. The event-related potentials elicited by these same stimuli in Experiment 2 showed a similar pattern of priming at the long SOA. At the short SOA, however, the priming effect for contextually inappropriate targets had a later onset than that for contextually appropriate targets. We interpret these data as indicating that both meanings of ambiguous words are not activated at the same time. The late priming effect for contextually inappropriate targets is discussed in terms of backward priming. 1987 Academic Press, Inc.
\end{abstract}

Ambiguous words have a single physical representation but two or more semantic representations. This quality makes such words a useful tool for examining the balance between data-driven (bottom-up) and concept-driven (top-down) processes in word recognition and reading/listening (Norman \& Bobrow, 1975). Three mutually exclusive possibilities exist for the cognitive processes engaged when a reader/listener encounters a lexical ambiguity: (1) only the semantic representation appropriate to the prior context is activated (selective access); (2) the most common or

This work was supported hy grants from NSF (BNS83-09243) and NIH (NS177778). C. Van Petten is supported by an NSF Graduate Fellowship. M. Kutas is supported by a Research Scientist Development Award (NIH 1K02MH00322). We are grateful to Steven Hillyard and two anonymous reviewers for helpful comments on the manuscript. A brief report of this study was presented at the meeting of the Society for Psychophysiological Research, Houston, Texas, 1985 (Van Petten \& Kutas, 1985). Correspondence should be addressed to Cyma Van Petten, Department of Neurosciences, M-008, University of California at San Diego, La Jolla, CA 92093. dominant meaning of the ambiguity is accessed first with the subordinate meaning accessed only if the dominant meaning proves inconsistent with the context (ordered access); and (3) both meanings of the ambiguity are activated, at least briefly (multiple access).

Evidence of selective access would imply that word recognition includes topdown processing by which sensory input is analyzed in light of the preceding context. Evidence of multiple access, in contrast, would suggest the presence of automatic, data-driven processing that acts independently of context and derives all possible meanings from the sensory input regardless of their relevance to the text. The orderedaccess model also involves an automatic process that invariantly selects a meaning for a word regardless of context.

The majority of studies of ambiguity resolution have supported the multiple access model (for a review see Simpson, 1984). Two primary experimental measures have been used: reaction times (RTs) in a phoneme monitoring task, and RTs in 
priming paradigms with color naming, lexical decision, or word naming tasks.

The phoneme monitoring paradigm relies on the assumption that accessing multiple meanings of a word drains more cognitive resources than does accessing one meaning. Reaction times in the secondary task of phoneme monitoring are thus used as an index of the number of meanings that were accessed for a given word. Several investigators have presented auditory sentences and observed slower responses to target phonemes following ambiguous than unambiguous words (Cairns \& Hsu, 1980; Cairns \& Kamerman, 1975; Foss, 1970; Foss \& Jenkins, 1973; Swinney \& Hakes, 1976).

Recent reviews have emphasized difficulties in interpreting the results of lexical ambiguity studies which employed the phoneme monitoring task. Mehler, Segui, and Carey (1978) noted that the comparison between ambiguous and unambiguous words was confounded by word length differences in some of the studies cited above. In addition, Newman and Dell (1978) pointed out that few of these studies controlled the degree of phonological similarity between the target phoneme and the initial phonemes of the ambiguous and unambiguous words. Simpson (1984) discussed these and other difficulties in the interpretation of phoneme monitoring studies.

Ambiguity studies using a priming paradigm have been less subject to methodological criticism and, in addition, have included a number of important variables such as the dominance of the sense of the lexical ambiguity used in the context, the strength of the context, and the temporal interval between words. A single trial in the priming studies to be discussed consisted of three stimuli: a semantic context biasing one sense of the ambiguity, the ambiguous word, and a target word which was related to one or the other sense of the ambiguity or to neither.

Several investigators who have used a sentence fragment as the context have obtained evidence that targets related to both meanings of the ambiguity are primed relative to unrelated targets (Conrad, 1974; Oden \& Spira, 1983; Onifer \& Swinney, 1981; Seidenberg, Tanenhaus, Leiman, \& Bienkowski, 1982; Swinney, 1979). Onifer and Swinney obtained this effect even when the sentence context biased the dominant meaning of the ambiguity and the target was related to the subordinate meaning, thus providing strong support for the multiple-access model versus either the selective- or ordered-access models. However, the results of Simpson (1981) are inconsistent with this conclusion in suggesting that dominance interacts with the strength of the sentence context. "Strength of context" in Simpson's experiments was determined by having subjects rate the degree to which sentences biased one of two possible interpretations of sentence-terminal ambiguous words. With a weak biasing context, Simpson found that targets related to the dominant sense were always primed, whereas targets related to the subordinant sense were primed only if the sentence context biased this meaning. Given a stronger sentence context, only targets related to the contextually appropriate sense of the ambiguous words were primed whether this was dominant or subordinate.

The importance of the "strength of context" variable has also been examined in a series of experiments by Seidenberg et al. (1982) who contrasted sentences which were disambiguated by only syntactic or pragmatic information with sentences that also contained a semantic associate of the ambiguous word. It was found that neither syntactic nor pragmatic constraints (e.g., "He bought a rose" or "Go to the store and buy a spade") prevented multiple access. However, sentences containing semantic associates (e.g., "The bridge player trumped the spade") yielded evidence of selective access for ambiguities with two noun meanings, but not for ambiguities with a noun and a verb meaning. Based on these results, Seidenberg et al. argued that the influence of strength of context in de- 
termining lexical access can be reduced to a single factor, lexical priming. These authors describe lexical priming as occurring within the same module that automatically derives candidate word meanings from the sensory input. According to this view, the finding of selective access under some circumstances does not necessarily implicate "top-down" context effects on lexical access. However, it is not clear how Seidenberg et al. (1982) determined that lexical priming alone was the important factor in producing selective access given that the various sentence types were not matched on other measures of contextual constraint (e.g., cloze probability) nor subjected to a rating procedure like Simpson's (1981).

Existing data do not allow a clear statement as to the influence of strength of context on ambiguity resolution, in part because of the difficulty in comparing stimulus materials across different experiments. However, in its strongest form, the multiple access model holds that lexical access is context independent. Thus, the more constraining the biasing context, the stronger will be the test of this model.

Another important factor in ambiguity resolution that can be quantified more easily is the temporal interval between the ambiguous word and its related targets. The multiple access model holds that the two senses of an ambiguous word are only briefly activated until a slower process selects the contextually appropriate meaning. Studies which have manipulated the interval between the ambiguous and target words have shown that time is indeed an important variable (Kintsch \& Mross, 1985; Onifer \& Swinney, 1981; Seidenberg et al., 1982). In general, a very short interval between the ambiguous word and the onset of the target word yields priming for targets related to both senses, whereas a longer interval yields priming for only targets related to the contextually appropriate sense.

In the experiments of Seidenberg et al. (1982), evidence of multiple access was ob- tained with zero delay between the offset of the ambiguity and the onset of the target word, but selective access was obtained with a delay of only $200 \mathrm{~ms}$. These results suggest that, although slower than the presumably automatic process which derives all of the possible meanings from the single letter string, the selection process is also completed very rapidly. It is thus possible that Simpson's (1981) finding of selective access with strong context was due to the 120 -ms delay between ambiguity and target.

The majority of ambiguity studies are then consistent with the idea that context plays little role in the initial stages of lexical access, but acts at a later point to select among candidate meanings activated by the sensory input. There is, however, an alternative to the multiple access model in accounting for the priming of targets related to the unbiased sense of ambiguous words in context. It is possible that context does act to constrain access to a single meaning of an ambiguous word, but that the subsequent presentation of a target word related to the unbiased meaning serves to activate this previously irrelevant sense via a "backward priming" mechanism. The newly activated, irrelevant sense of the ambiguity would then be processed concurrently with its related target, leading to a shorter RT for this target. According to this proposal the presentation of two words with very little time intervening is functionally equivalent to presenting the two words simultaneously.

There have been several demonstrations that lexical decision is faster for pairs of simultaneously presented words if they are related than if they are not (Carroll \& Kirsner, 1982; Fischler, 1977a, 1977b; Meyer \& Schvaneveldt, 1971). Moreover, Kiger and Glass (1983) have demonstrated that the subsequent presentation of a related prime can result in facilitated lexical decision for the target word if the interval between the two words is short.

The existence of backward priming has 
clear implications for lexical ambiguity research. It is possible that the finding of multiple access may be an artifact of the experimental paradigm designed to measure it. The target word, rather than serving as a mere probe to determine how the preceding ambiguous word was processed, may also serve as a source of context in the interpretation of the ambiguity. The critical issues in resolving this question are those of time.

One question is whether the SOAs which produce multiple access are also those which lead to backward priming. Kiger and Glass (1983) observed backward priming in a word-pair lexical decision task at SOAs of less than $130 \mathrm{~ms}$, while Seidenberg et al. (1982) observed multiple access in a sentence paradigm at delays of less than 200 ms. Allowing for the additional complexity of processing a sentence context over a single word context, these values are rather close to one another.

A second empirical question is whether backward priming acts quickly enough to influence the behavioral response being measured. Seidenberg and colleagues have argued that, unlike the lexical decision task, the naming task is not susceptible to backward priming effects (Seidenberg, Waters, Sanders, \& Langer, 1984). However, it is not clear that the "backward priming" discussed by Seidenberg et al. (1984; see also Koriat, 1981) is the same phenomenon as that observed by Kiger and Glass. Seidenberg measured both naming and lexical decision times for the second words of asymmetrically related word pairs, such as "stick-lip," which were highly related only in the "backward" direction. The SOA between the first and second word of a pair was $500 \mathrm{~ms}$. Thus, while the semantic relations between primes and targets were "backward," the temporal relations were "forward" in that the prime preceded the target. Given the relatively long SOA, it seems unlikely that prime and target recognition would have overlapped in time. The finding that naming latencies are unaffected by (semantically) backward priming may, then, have little or no bearing on the question of whether naming latencies may be affected by (temporally) backward priming.

In the sense that we will use the term, "backward priming" refers to temporal overlap in the processing of two words, and can be thought of as "mutual priming" analogous to that which occurs between two simultaneously presented words.

The present study was designed to provide evidence about the time course of meaning activation via the recording of event-related brain potentials (ERPs). The brain's electrical response to a word can be recorded over a continuous interval of several seconds. Previous research has shown that the ERP response to a single word is sensitive to the degree to which that word has been semantically primed by a preceding sentence fragment or single word. Kutas and Hillyard (1980a, 1980b, 1980c, 1983, 1984) have shown that semantically incongruous words at the ends of sentences produce a negative peak around $400 \mathrm{~ms}$ poststimulus (the $\mathrm{N} 400$ ), whereas semantically appropriate sentence completions typically produce a broad positive shift in the ERP. Kutas and Hillyard presented their sentences visually, but it has since been shown that the $\mathrm{N} 400$ response to semantic incongruity is not specific to the modality of presentation, and appears following incongruous words in speech (Holcomb, 1985; McCallum, Farmer, \& Pocock, 1984) and American Sign Language (Neville, 1985; Kutas, Neville, \& Holcomb, in press).

The N400 component differs from the sensory components of the ERP (such as the N100, P200, etc.) and from the cognitive P300 component in being insensitive to experimental manipulations which do not involve linguistic variables (Besson \& Macar, in press; Kutas \& Hillyard, 1980a, 1980b; McCallum et al., 1984). The N400 provides an index of semantic processing and is closely linked to behavioral mea- 
sures of semantic priming. For example, in an experiment using only semantically congruous sentence completions, it was shown that the amplitude of the N400 varied inversely with the cloze probability of the terminal word (Kutas \& Hillyard, 1984). These results parallel those obtained with the lexical decision task (Fischler \& Bloom, 1979), in that words of low cloze probability elicit large N400s and prolonged lexical decision times. Similarly, the N400 is of larger amplitude following unrelated than related items in studies using pairs or lists of words (Bentin, McCarthy, \& Wood, 1985; Harbin, Marsh, \& Harvey, 1984; Holcomb, in press; Kutas, 1985; Rugg, 1985).

The present study was designed to use the N400 component of the ERP as a measure of semantic priming and to use this measure to compare the relative time course of semantic activation of contextually biased and unbiased meanings of ambiguous words. Two experiments are reported. The first is similar to previous ambiguily studies in using naming latency as the dependent measure. The primary purpose of Experiment 1 was to ensure that the stimulus materials constructed for this study would produce the expected priming effects for both contextually appropriate and inappropriate semantic associates of ambiguous words relative to unrelated target words. In Experiment 2, ERPs were recorded to these same stimuli.

\section{EXPERIMENT 1}

\section{Methods}

\section{Stimulus Construction}

One hundred and twenty words with two distinct and unrelated meanings were selected. Half of these homographs had both a noun sense and a verb sense; the other half had two noun meanings. Published norms were used to select the subordinate sense of the homographs (Geis \& Winograd, 1974; Gorfein, Viviani, \& Leddo, 1982; Kausler \& Kollasch, 1970; Nelson,
McEnvoy, Walling, \& Wheeler, 1980; Perfetti, Lindsey, \& Garson, 1971). No published data could be found for 18 of the 120 homographs used; in these cases the authors chose what seemed to be the less common sense of the word.

Each homograph was used in its subordinate sense to complete a sentence fragment. Biasing the sentence contexts toward the less common meanings of the homographs ensured that the "contextually appropriate" targets words would be related to this subordinate sense, whereas "contextually inappropriate" targets would be related to the more dominant meaning. This design thus allows a distinction between the selective access model on the one hand and the multiple and ordered access models on the other hand, without being able to distinguish between the predictions of the latter two models. Any priming of the contextually inappropriate targets could arise from either exhaustive access of all of the homographs' potential meanings or from a tendency to access the dominant meaning regardless of context.

An attempt was made to construct moderate to highly constraining sentence fragments for which the ambiguous words were the most likely completions. The success of this attempt was assessed by asking a separate group of 20 subjects to complete each sentence fragment with a single word. Each sentence was completed with the appropriate homograph by an average of 11 out of these 20 subjects. Representative sentences are shown in Table 1.

Three target words were selected to follow each homographic sentence; one which was related to the sense of the homograph used in its sentence ("contextually appropriate"'), one related to the other sense of the word ("contextually inappropriate"'), and one which was unrelated to either sense ("unrelated"). There were no significant differences among the threc target types in frequency of usage (Kucera \& Francis, 1967): contextually appropriate targets, $99+157(M+S D)$; 
TABLE 1

SAMPLE STIMULI FOR EXPERIMENTS 1 AND 2

\begin{tabular}{|c|c|c|c|}
\hline & $\begin{array}{c}\text { Contextual } \\
\text { target }\end{array}$ & $\begin{array}{l}\text { Unbiased } \\
\text { target }\end{array}$ & $\begin{array}{l}\text { Unrelated } \\
\text { target }\end{array}$ \\
\hline \multirow{6}{*}{$\begin{array}{l}\text { Homograph sentence } \\
\text { The gambler pulled an ace from the bottom of the deck. } \\
\text { It is not legal for an employer to consider a person`s } \\
\text { religion or race. } \\
\text { The logger cut down the tree with a chain saw. } \\
\text { The bicycle mechanic fixed the flat tire and repaired the } \\
\text { broken spoke. }\end{array}$} & & & \\
\hline & cards & ship & parent \\
\hline & & & \\
\hline & color & run & art \\
\hline & $\mathrm{ax}$ & look & proof \\
\hline & wheel & talked & pill \\
\hline Filler sentence & $\begin{array}{l}\text { Related } \\
\text { target }\end{array}$ & & $\begin{array}{c}\text { Unrelated } \\
\text { target }\end{array}$ \\
\hline He bought a quart of milk and a dozen eggs. & bacon & & buckle \\
\hline The sweater was knitted from blue and grey wool. & lamb & & cigar \\
\hline
\end{tabular}

contextually inappropriale targets, $108+$ 148; unrelated targets, $109+141 ; F(2,359)$ $=0.18, \mathrm{NS})$. No attempt was made to match the initial phonemes of the different classes of target words. A list of the homographs and targets used appears in Appendix 1 .

An additional 120 sentences were completed with unambiguous words ("filler sentences"). Related and unrelated target words were chosen for each filler sentence.

Three separate stimulus lists were constructed. In each list 40 of the homographic sentences were followed by a contextually appropriate target, 40 by a contextually inappropriate target, and 40 by an unrelated target. The type of target was counterbalanced so that, across lists, each homographic sentence was followed by each type of target. Half of the filler sentences in each list were followed by related targets, and hall by unrelated. Within each subject group, one-third of the subjects saw each list.

\section{Stimulus Presentation}

Words were displayed in the form of brightened dot matrices on a CRT controlled by an Apple II microcomputer. The duration of each word was $200 \mathrm{~ms}$. Each sentence was presented one word at a time with an SOA (onset of one word to onset of next) of $900 \mathrm{~ms}$. Each sentence ended with a period such that subjects were aware of sentence terminations. Target words appeared at a location which was slightly below that of the sentence words to further differentiate target words from sentence words. For half of the subjects, target words appeared $16 \mathrm{~ms}$ after the offset of sentence terminal words to yield a total stimulus onset asynchrony (SOA) of 216 ms. For the other half of the subjects, sentence-target SOA was $700 \mathrm{~ms}$.

Our 216-ms SOA condition is probably quite similar to the zero delay condition of previous ambiguity experiments using cross-modal presentation (Onifer \& Swinney, 1981; Seidenberg et al., 1982; Swinney, 1979). The effective stimulus onset asynchrony in these experiments would have been equal to the duration of the auditorily presented ambiguity. Given a normal rate of speech, the SOA between ambiguity and target might then have been 200-300 ms.

\section{Subjects}

Forty-two young adults (20 female, age range 18-25 years) were paid for participating in the experiment. All had normal or corrected-to-normal vision.

\section{Procedure}

Subjects were tested one at a time in a 
sound-attenuating chamber. They were instructed to read each sentence in order to complete a multiple-choice questionnaire about their contents at the end of the experiment, and to say each target word aloud as fast as possible. Each subject was given a practice run consisting of 10 unambiguous sentences, 5 with related and 5 with unrelated targets.

Assignment to SOA group and stimulus list was pseudorandom, with the constraint that 21 subjects were in each SOA group, and 7 subjects within each SOA saw a given stimulus list.

Voice onset was recorded via a microphone and a voice-activated trigger. The responses were recorded by a PDP 11/34 computer together with stimulus codes.

\section{Data Analysis}

Incorrect responses and those responses that failed to trigger the microphone were excluded from analysis, as were reaction times shorter than $400 \mathrm{~ms}$ or longer than $900 \mathrm{~ms}$. Approximately $3.2 \%$ of the trials were lost due to these reasons.

\section{Results}

\section{Filler Targets}

The means of each subject were subjected to a $2 \times 2$ analysis of variance (ANOVA) with repeated measures, using SOA as a between-subjects variable and target type as a within-subjects variable. As seen by the mean naming latencies shown in Table 2, the long SOA group responded more quickly than the short SOA

TABLE 2

NAMING LATENCIES IN EXPERIMENT 1

\begin{tabular}{lcc}
\hline \multicolumn{1}{c}{ Target type } & 200 SOA & 700 SOA \\
\hline Filler related & $602(70)$ & $542(64)$ \\
Filler unrelated & $627(85)$ & $569(78)$ \\
Homograph biased & $591(73)$ & $547(71)$ \\
Homograph unbiased & $617(77)$ & $562(69)$ \\
Homograph unrelated & $635(85)$ & $571(71)$ \\
\hline
\end{tabular}

Note. SOA, stimulus onset asynchrony. $M$ and $S D$ in ms. $N=21$ for both SOAs. group for both target types, $F(1,40)=6.69$, $p<.02$. Responses to related targets were faster than to unrelated targets, $F(1,40)=$ $61.0, p<.001$. There was no significant interaction between SOA and target type $F(2,80)=0.05, \mathrm{NS}$.

\section{Homograph Targets}

The means of each subject were subjected to an initial $2 \times 3$ ANOVA with SOA and target type as factors. As for the filler data, there were significant main effects of SO $\Lambda, F(1,40)=5.62, p<.05$, and target type, $F(2,80)=59.6, p<.001$. There was also a significant interaction of SOA by target type, $\boldsymbol{F}(2,80)=5.22, p<.01$. A more detailed analysis of the interaction was carried out using the Dunnett test for comparisons with the control (unrelated) condition (Keppel, 1982). Responses to contextually appropriate targets were faster than to unrelated targets at both SOAs: long SOA $F(1,20)=21.0, p<.01$; short SOA, $F(1,20)=65.6, p<.01$. Responses to the contextually inappropriate targets were faster than unrelated targets at the short SOA but not at the long SOA: long SOA, $F(1,20)=5.58, p>.05$; short SOA, $F(1,20)=21.2, p<.01$. A post hoc comparison (Tukey test (Keppel, 1973)) showed that, although faster than unrelated responses, contextually inappropriate responses were slower than contextually appropriate responses at the short SOA, $F(1,20)=48.9, p<.01$.

\section{Discussion}

Our results replicate those of previous studies in showing that, despite a sentential context biasing one reading of an ambiguous word, targets related to both senses are primed if the temporal interval between the ambiguous prime and its target is short (Kintsch \& Mross, 1985; Onifer \& Swinney, 1981; Seidenberg et al., 1982). Note that in the present study, the contextually inappropriate targets were related to the dominant, higher frequency sense of the homographs used. The RT facilitation 
observed for these targets is thus consistent with either the "multiple access" or "ordered access" model of ambiguity resolution.

Although faster than the RTs to unrelated targets, the contextually inappropriate target RTs were slower than those to contextually appropriate targets. This effect has been reported in past studies (Onifer \& Swinney, 1981; Simpson, 1981), although it has not always been statistically significant (Seidenberg et al., 1982; Swinney, 1979; see also Simpson, 1984). A greater degree of priming for contextually appropriate targets over contextually inappropriate targets may reflect preferential processing of the biased meaning of ambiguous words. Alternatively, it may reflect direct priming of the contextually appropriate targets by the sentence contexts independent of the ambiguous words.

In the present study, many (76 out of 120) of the homograph sentence contexts contained words which were lexically associated to the contextually appropriate targets (e.g.. "The gambler pulled an ace from the bottom of the deck. cards"). The RTs to the contextually appropriate probes may then have reflected priming by intermediate words in the sentence as well as by the terminal homographs, a benefit not enjoyed by the contextually inappropriate targets. However, these lexically associated intermediate words occurred, on the average, 5.7 words (or $5.2 \mathrm{~s}$ ) prior to the target words. We do not know if a lexical priming mechanism, when extended over so many words, could account for the differential priming of contextually appropriate and contextually inappropriate targets. It has been reported that semantic priming drops off sharply with even a single intervening item in word lists (Dannenbring \& Briand, 1982; Foss, 1982), but can be maintained over intervening material in prose passages (Foss, 1982). The present case falls somewhere between a word list and a passage, and the question of priming between sentence intermediate words and targets remains open. This issue will be examined at greater length in Experiment 2.

The primary purpose of Experiment 1 was to validate this set of sentences and targets for producing reaction time priming of both contextually appropriate and inappropriate targets of homographs. This purpose achieved, we proceeded to record ERPs to the same set of stimulus materials.

\section{EXPERIMENT 2}

Methods

\section{Subjects}

Eighteen paid volunteers were assigned to the short SOA group, and 15 to the long SOA group. All subjects had normal or corrected-to-normal vision, and were righthanded ( 5 with left-handed relatives). The age range was 18 to 25 years and 11 of the subjects were female. None of these subjects had participated in the previous experiment.

\section{Stimuli}

The stimulus materials were the same as those in Experiment 1, with the following exception. ERP subjects were assigned a task other than naming because of the electrical artifacts associated with speech (electromyogram, glossokinetic potential, respiratory potentials, etc.) (see Grozinger, Kornhuber, Kriebel, Szirtes, \& Westphal, 1980 , and Picton \& Stuss, 1984, for reviews of these problems). This task was a letter search of the target word performed subsequent to its presentation. Single trials then consisted of the sentences and "target" words as beforc, but a single letter of the alphabet appeared $1500 \mathrm{~ms}$ after each target word. Letters were selected pseudorandomly with the constraint that $50 \%$ of each target type were followed by a letter that had been in the word, and $50 \%$ by a letter that had not been in the word. ERP responses to these target letters were not analyzed; rather the task was selected solely to ensure that subjects attended to the "target" words. We will continue to 
refer to these words as "targets" for the sake of consistency with Experiment 1, but note that the ERP subjects were not required to make an overt response to these words. It has been shown in previous research that ERPs recorded during such a letter search task reliably discriminate between primed and unprimed words although no behavioral response is required to the words themselves (Kutas, 1985; see Kutas \& Van Petten, in press).

The specifics of stimulus presentation were as in Experiment 1.

\section{Procedure}

Subjects were tested in one session that lasted 3 to $3.5 \mathrm{~h}$, while reclining in a comfortable chair. They were instructed to read each sentence in order to answer a multiple-choice questionnaire at the end of the experiment, and to read each target word in order to decide if the subsequent letter appeared in the target word. Subjects pressed one of two buttons held in either hand on each trial to indicate "letter present" or "letter absent." Half of the subjects in each group used the right hand for "letter present" and the left for "letter absent," and the other half the reverse.

\section{Recording System}

EEG activity was recorded from 10 scalp electrodes; each referred to an average of the left and right mastoids. Eight were placed according to the International $10-20$ system at frontal $(\mathrm{Fz})$, central $(\mathrm{Cz})$, parietal $(\mathrm{Pz})$, and occipital $(\mathrm{Oz})$ midline locations, as well as at frontal and central lateral sites (F3,F4,C3,C4). Symmetrical posterior temporal electrodes were placed lateral (by $30 \%$ of the interaural distance) and $12.5 \%$ posterior to the vertex. Eye movements were monitored via an electrode placed below the right eye and referred to the mastoids for vertical movements and blinks, and via a right-to-left canthal bipolar montage for horizontal movements.

The midline and EOG recordings were amplified with Grass 7P122 preamplifiers (system bandpass 0.01 to $35 \mathrm{~Hz}$, half-amplitude cutoff). The EEG from the lateral scalp leads were amplified with Grass 7P511 preamplifiers modified to have an 8-s time constant (high-frequency half-amplitude cutoff $=60 \mathrm{~Hz}$ ).

\section{Data Analysis}

Analog-to-digital conversion of the EEG, $\mathrm{EOG}$, and stimulus trigger codes was performed online by a PDP 11/45 computer. A 2048-ms epoch of EEG, beginning $200 \mathrm{~ms}$ before the onset of sentence terminal words, was averaged at a sampling rate of $125 \mathrm{~Hz}$. Trials characterized by excessive eye movement or amplifier blocking were rejected, approximately $15 \%$ of the trials.

ERPs were quantified by computer as the mean voltage within a latency range, relative to the $200 \mathrm{~ms}$ of activity preceding the sentence terminal words. Two latency windows were used to quantify the response to target words. A 300- to 700-ms post-target window was chosen to encompass the usual latency band of the N400 response (Fischler, Bloom, Childers, Roucos, \& Perry, 1983; Kutas \& Hillyard, 1980a, 1980b, 1980c; McCallum et al., 1984). A later latency band of 700 to 1100 ms post-target was also measured.

\section{Results}

\section{Filler-Target Responses}

The responses to unambiguous sentence completions and subsequent target words at both SOAs are shown in Figure 1. It can be seen that the overall waveshape of the response was quite different at the different SOAs. At the 700-ms SOA, the N100 (negative peak at about $100 \mathrm{~ms}$ ) and P200 (positive peak at about $200 \mathrm{~ms}$ ) waves elicited by the terminal word of the sentence were followed hy a negative-going anticipatory potential (i.e., contingent negative variation, $\mathrm{CNV}$ ) before the presentation of the target word, which then elicited similar N100-P200 ERP components. The 200-ms SOA response, in contrast, was a com- 


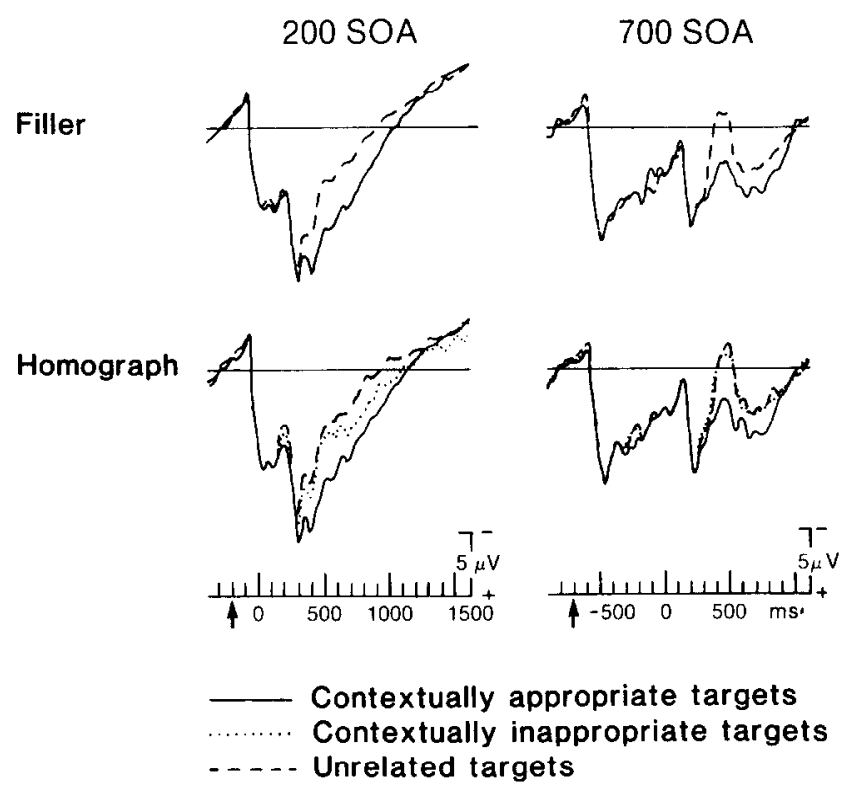

FIG. 1. Prime-target stimulus onset asynchrony. Grand average ERPs to ambiguous (homographs) and unambiguous (filler) sentence terminal words and subsequent targets. Onset of the sentence terminal words is indicated by an arrow. Onset of the targets is at $0 \mathrm{~ms}$. The ERPs were recorded at a midline central site $(\mathrm{Cz})$. SOA, stimulus onset asynchrony.

pound ERP in which the responses to terminal and target words overlap. ${ }^{1}$

It is important to note, however, that where the ERP to the terminal words could be isolated, namely in the 700-ms SOA data, there were no differences between the various conditions before the presentation of the target words. This was to be expected since the different conditions included responses from the same sentences

1 There are two factors which act to make the overall waveshape of the ERP different for the two SOAs. One is a single superposition, or overlapping. of the ongoing ERPs to the terminal word of the sentence and the target word. An algebraic subtraction routine could, in principle, cancel this superposition effect. However, this is not a tenable procedure for obtaining the "true"' ERP to a single word as there are also different physiological/cognitive processes at work in different SOAs. Much research has been devoted to the potentials which develop during the interval between two stimuli presented at a fixed rate (see Rohrbaugh \& Gaillard, 1983, for a review of the CNV). The waveshape and amplitude of these potentials are sensitive to the duration of the interval; we have thus confined our experimental comparisons to within-SOA data. counterbalanced across subjects. Therefore, any ERP differences among conditions can be attributed to the target words. It can be seen that the difference between related and unrelated targets at the two SOAs was similar, consisting of greater negativity (an N400) to the unrelated targets. We will focus, therefore, on the relative difference between the ERPs to related and unrelated targets within each SOA.

SOA $(700 \mathrm{~ms})$. Figure 1 shows that the unrelated targets elicited substantially larger $\mathrm{N} 400$ s than the related targets. The negative difference between the two target types begins around $300 \mathrm{~ms}$ after the target and continues for several hundred milliseconds. The mean amplitudes of each subject's ERPs were subjected to a repeated measures ANOVA using target type (related and unrelated), latency window (300 to $700 \mathrm{~ms}$ post-target and 700 to 1100 ms post-target), and electrode site (10 levels) as factors. There was a mean effect of target type, $F(1,14)=8.05, p<.02$, reflecting the greater negativity for unrelated 
targets. There was also an interaction of target type by latency window, $F(1,14)=$ $5.97, p<.03$, reflecting the greater difference between related and unrelated targets in the early (300-700 ms post-target) portion of the waveform than in the late (700-1100 ms post-target). Separate ANOVAs were carried out to test the target type effect within each latency range; the significance of these $F$ values was evaluated by the Dunnett test. The relatedness effect was significant in both latency windows: early, $F(1,14)=9.07, p<.05$; late, $F(1,14)=7.03, p<.05$.

SOA $(200 \mathrm{~ms})$. ERPs obtained at the 200ms SOA were similar to those of the $700-\mathrm{ms}$ SOA in that unrelated targets elicited more negativity than related targets bcginning about $300 \mathrm{~ms}$ after the target word. The ERPs obtained at the 200-ms SOA were analyzed in the same manner as the $700-\mathrm{ms}$ SOA waveforms. There was a mean effect of target type, $F(1,17)=43.9, p<.001$, and an interaction between target type and latency window, $F(1,17)=16.0, p<.001$. Separate comparisons showed that unrelated targets elicited greater negativity in both the early, $F(1,17)=53.6, p<.01$, and late, $F(1,17)=22.9, p<.01$, portions of the ERP response.

\section{Homograph-Target Responses}

SOA $(700 \mathrm{~ms})$. As in the filler data, unrelated targets elicited a large N400 while the contextually appropriate targets (see Figure 1) elicited a much smaller N400. The ERP response to contextually inappropriate targets appears very similar to that for the unrelated targets. The mean amplitudes of each subject's ERP were subjected to a repeated-measures ANOVA with target type ( 3 levels), latency window (2 levels), and electrode site (10 levels) as factors. There was a main effect of target type, $F(2,14)=8.13, p<.002$, but no significant interaction of target type by latency, $F(2,28)=2.47$, NS. The main effect of target type in this overall ANOVA is not very informative; the Dunnett test was used to compare the contextually appropriate and contextually inappropriate target responses to the unrelated response. This procedure showed that contextually appropriate target ERPs differed from unrelated target ERPs in both the early and late portions of the response: early, $F(1,14)=$ $11.3, p<.05$; late, $F(1,14)=8.67, p<.05$. In contrast, the inappropriate target responses did not differ from the unrelated response in either portion of the waveform: early, $F(1,14)=0.21$, NS; late, $F(1,14)=$ 0.005 , NS.

SOA $(200 \mathrm{~ms})$. As in the long SOA data, the unrelated targets elicited a larger N400 than did the contextually appropriate targets. Figure 1 shows that the responses to unrelated and contextually appropriate targets begin to separate as early as $300 \mathrm{~ms}$ after the target word. Unlike the long SOA data, the response to contextually inappropriate targets does not appear to be identical to the response to unrelated targets throughout the recording epoch. The contextually inappropriate target ERP initially resembles the response to unrelated targets, but subsequently becomes more positive and resembles the response to contextually appropriate targets.

The ERPs obtained at the 200-ms SOA were analyzed in the same manner as the long SOA ERPs. The overall ANOVA showed significant main effects of target type, $F(2,17)=18.9, p<.001$, and latency, $F(1,17)=46.5, p<.001$. There was also a significant interaction of target type by latency, $F(2,34)=4.74, p<.02$. Pairwise comparisons showed that the contextually appropriate target responses differed from the unrelated in both early and late portions of the waveform: early, $F(1,17)=$ $52.8, p<.01$; late, $F(1,17)=16.9, p<.01$. The contextually inappropriate target responses, in contrast, differed significantly from the unrelated responses in the late portion of the response, $F(1,17)=13.2, p$ $<.01$, but not in the early portion of the response, $F(1,17)=1.27$, NS.

Additional post hoc tests were con- 
ducted on the contextually inappropriate target FRP to further describe its similarity or dissimilarity to the contextually appropriate and unrelated response. Pairwise ANOVAs were computed; $F$ values were evaluated via the Tukey test (Keppel, 1973). The contextually inappropriate target ERP was significantly different from the contextually appropriate ERP during the $300-$ to $700-\mathrm{ms}$ portion of the response, $F(1,17)=17.7, p<.01$. The difference between contextually appropriate and inappropriate responses in the $700-$ to 1100 -ms latency range, however, failed to reach significance, $F(1,17)=4.05, p>.05$.

It is of some interest to track the time course of the brain responses to the three target types and, in particular, to determine when the contextually inappropriate response deviated from the unrelated response and took on the likeness of the contextually appropriate response. The ERPs averaged across subjects show that the contextually biased response diverges from those to the other two target types at about $300 \mathrm{~ms}$ after target onset. The contextually inappropriate response appears to diverge from the unrelated response at about 500 ms following the target. The latency windows originally selected for the analysis of individual subjects' data are, however, too broad to evaluate these impressions about the onset latencies of the experimental effects.

A more fine-grained analysis was provided by comparing successive $25-\mathrm{ms}$ epochs of the responses following presentation of different target types. The 300- to $325-\mathrm{ms}$ epoch was the earliest point at which the contextual target responses differed from the unrelated responses, $F(1,17)$ $=20.3, p<.001$. Similarly, the contextually appropriate target responses began to differ from the inappropriate targets in this same time band, $F(1,17)=9.77, p<$ .01 . This relationship also held for the comparisons between filler related and unrelated targets, $F(1,17)=5.59, p<.05$.

In contrast, none of the comparisons be- tween contextually inappropriate and unrelated target ERPs conducted within the 300- to 500-ms latency region revealed any significant effects due to the semantic relationship between homograph and target. Beginning with the $500-$ to $525-\mathrm{ms}$ band (and in each 25-ms epoch in the 500- to 700 -ms region) there was a significant interaction of relationship type with electrode site, $F(9,153)=6.08, p<.001$. The interaction indicates that for this latency band, the unrelated/contextually inappropriate difference was significant at the three most posterior midline sites only: $\mathrm{Cz}, F(1,17)=$ $5.10, p<.05 ; \mathrm{Pz}, F(1,17)=5.38, p<.05$; $\mathrm{Oz}, F(1,17)=5.35, p<.05$. A significant main effect of target type did not appear until the $700-$ to $725-\mathrm{ms}$ band, $F(1,17)=$ 7.97, $p<.05$.

In summary, the ERPs to contextually inappropriate targets and to unrelated targets were highly similar during the first $500 \mathrm{~ms}$ following the onset of the target. The contextually inappropriate target ERP became more like the contextually appropriate ERP between 500 and $700 \mathrm{~ms}$ after the target presentation, and became statistically indistinguishable from the contextually appropriate response in the 700 - to 1100-ms epoch.

\section{Discussion}

The present results extend those of previous ERP experiments by demonstrating that the amplitude of the $\mathrm{N} 400$ reflects priming across a sentence boundary, as well as priming by a sentence fragment or single word (Bentin et al., 1985; Fischler et al., 1983, 1984; Harbin et al., 1984; Holcomb, in press; Kutas \& Hillyard, 1980a, 1980b, 1980c, 1983, 1984; Rugg, 1985). Targets with no semantic relationship to the final word of a sentence elicit a larger $\mathrm{N} 400$ component than do related target words. This relationship between N400 amplitude and priming held for targets following both ambiguous and unambiguous terminal words.

It should be noted that while we speak of 
fluctuations in the amplitude of a negative wave, the $\mathrm{N} 400$, the data can be described in terms of fluctuations in the amplitude of a positive wave in the same latency range. These descriptions are equivalent for our present purposes. The relationship between priming and positivity, or lack of priming and negativity, can be used to test two opposing models of ambiguity resolution. According to the selective access model, contextually inappropriate targets should be processed as if they were unrelated to the preceding ambiguity and so should elicit N400s of equal amplitude, latency, and duration to those elicited by completely unrelated targets at any SOA. The multiple access model, in contrast, predicts that the priming of contextually inappropriate targets is dependent on SOA. In this case, the contextually inappropriate target ERP should be identical to the contextually appropriate target ERP at the short SOA when both senses of the ambiguity are still activated, and identical to the unrelated ERP when a longer interval allows selection of the contextually appropriate meaning.

Our finding of equivalent N400s for contextually inappropriate and unrelated targets at the long SOA is compatible with either the multiple or selective access model. On the other hand, the ERPs obtained with the $200-\mathrm{ms}$ SOA do not fit neatly into the pattern predicted by either model. We cannot accept the selective access model in its simplest form because the contextually inappropriate and unrelated ERPs at the short SOA do differ. The greater positivity of the contextually inappropriate ERP relative to the unrelated one suggests that the contextually inappropriate targets, at some point, were processed in a manner similar to contextually appropriate targets. However, the ERPs to unrelated and contextually inappropriate targets do not differ until $500 \mathrm{~ms}$ have passed since the presentation of the target. In contrast, the ERPs to unrelated and contextually appropriate targets differ as early as $300 \mathrm{~ms}$ post-target. The $200-\mathrm{ms}$ lag be- tween the onset of these two effects is not consistent with the multiple access model of simultaneous and parallel activation of both senses of ambiguous word.

How can we account for the existence, but late onset, of the contextually inappropriate/unrelated target difference? Some possible interpretations must be discounted by the lack of any difference between unrelated and contextually inappropriate targets in the long SOA condition. For instance, if the late priming-related positivity were due to the delayed realization that the contextually inappropriate targets were related to the homographs, although not in the way originally expected, there should be a similar "double take" effect some $500 \mathrm{~ms}$ after the target in the long SOA condition. There was not. Similarly, one might suppose that the subjects engaged in a deliberate attempt to recover the unbiased meanings of the homographs (after the experiment, several subjects in both SOA conditions reported noticing these), and that the late effect is the product of slow strategic priming of the sort described by Neely (1977). Although subjects in the long SOA condition had more time to engage strategic or attentional processes, their brain responses did not differentiate between contextually inappropriate and unrelated targets. Thus, this explanation seems unlikely.

Finally, it has been suggested that the differing onset latencies of the priming effects we report for contextually appropriate and inappropriate targets reflect the targets' differential relationships to intermediate sentence words, rather than their relationships to the terminal homographs. Many of the contextually appropriate targets had semantic relationships to intermediate words while the contextually inappropriate targets did not.

In this view, the priming effect for contextually appropriate targets might be composed of two parts: an early part (onset at $300 \mathrm{~ms}$ post-target) due to direct priming by intermediate words, and a late part (onset at $500 \mathrm{~ms}$ ) due to priming by the terminal homograph. The apparently different onset 
latencies for priming of contextually appropriate and inappropriate targets would only reflect the fact that contextually inappropriate targets lack the early, intermediateword component of the priming effect. If this were true, the present results might reflect equal and simultaneous priming of both target types by the terminal homographs, thus supporting the multiple access hypothesis. We find this explanation unlikely, although logically possible, because $500 \mathrm{~ms}$ seems very long for the onset of a forward priming effect.

It is not possible to refute this proposal via analysis of the ERPs to homograph targets. The intermediate word-target relationships were a necessary consequence of our effort to construct constraining sentence contexts for the homographs. Note, however, that this alternative explanation is not specific to sentences with ambiguous words, but makes general predictions about the onset latency of the ERP priming effect for targets which have been primed solely by the terminal word of a sentence. A substantial proportion of the filler sentences contained no intermediate words related to the filler targets (see Appendix 2). According to the proposal outlined above, the priming effect for the related targets of these sentences should onset at the same time as the priming effect for the contextually inappropriate targets of homograph sentences.

Filler sentences were thus split into two conditions, "high associative context" and "low associative context" and the ERPs to related targets following "low context" fillers averaged separately for the subjects in the short SOA group. For each subject, 38 of the original 60 related targets fell into this condition. ${ }^{2}$ Figure 2 compares the ERP difference wave (priming effect) for "low associative context" fillers with those for

\footnotetext{
2 The remaining 22 trials constituting the "high associative context" condition were insufficient for an adequate signal-to-noise ratio in averaging the ongoing electroencephalogram to form an ERP. The "low associative context" condition is, however, of greater relevance here.
}

contextually related and contextually inappropriate homograph targets. It can be seen that the "low context" filler effect substantially precedes the contextually inappropriate target effect, although it does begin slightly later than the priming effect for contextually appropriate targets. The onset latency of the "low context" filler priming effect was determined in the same manner as latencies in the other conditions (see Results). The first time window in which these related and unrelated targets differed was $350-375 \mathrm{~ms}$ poststimulus, $F(1,17)=10.9, p<.004$. The 50 -ms lag between the onset of this priming effect and that for the contextually appropriate targets of homographs may well be due to the lack of intermediate word priming. This small latency shift cannot, however, account for the much longer delay in priming of contextually inappropriate homograph targets; the $500-\mathrm{ms}$ onset of this priming effect is clearly much later than the normal onset latency for priming by sentence terminal words.

The hypothesis most consistent with our results is that backward priming of the type reported by Kiger and Glass (1983) occurred in the 200-ms SOA but not in the 700-ms SOA condition. It seems reasonable to assume that there was grcater temporal overlap between terminal word and target word processing in the short SOA condition than in the long SOA condition. Thus, target words presented shortly after the terminal words might have served as second sources of context in the as yet incomplete interpretation of these words. When the terminal words were ambiguous, contextually inappropriate targets could have served to activate the sense of the word which had not been primed by the preceding sentence. The concurrent processing of this newly activated meaning and its related target would, in this view, have led to the observed priming effect for the contextually inappropriate targets. One would expect such mutual priming between the ambiguity and its contextually inappropriate target to lag behind priming between 


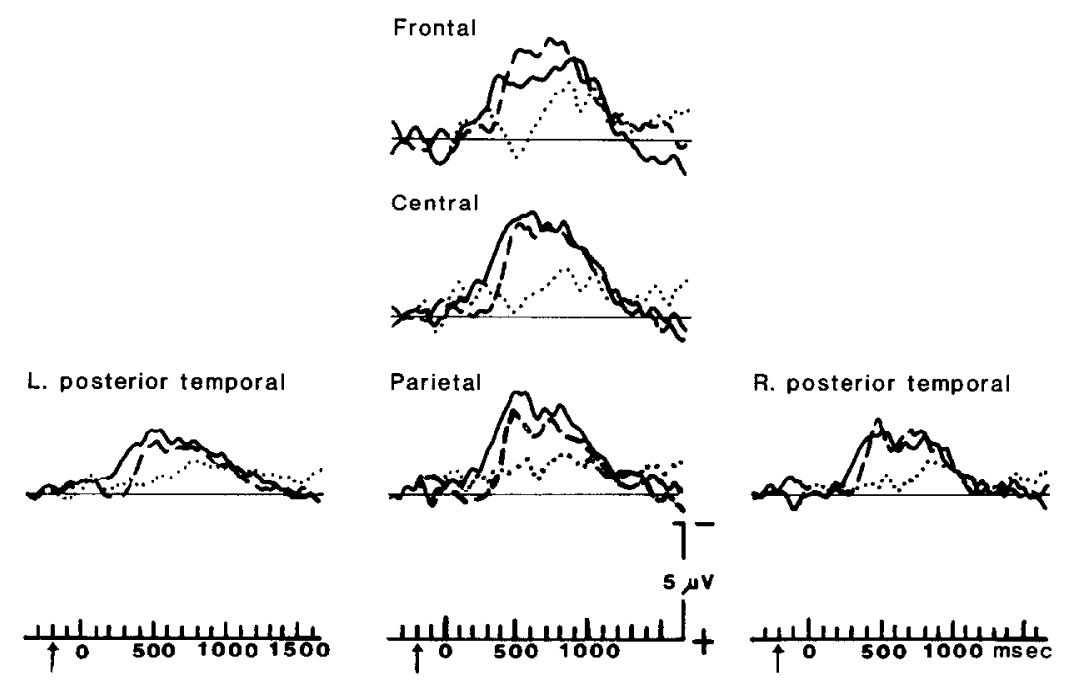

FIG. 2. Grand average difference waves for the 200-ms SOA. Onset of the sentence terminal words is indicated by an arrow. Onset of the targets is at $0 \mathrm{~ms}$. The solid line is the result of subtracting the ERP to contextually appropriate targets from the ERP to unrelated targets following homographs. The dotted line is the result of subtracting the ERP to contextually inappropriate targets from the ERP to unrelated targets following homographs. The dashed line is the result of subtracting the ERP to related targets following filler sentences of low associative context (see text) from the ERP to unrelated filler targets.

the ambiguity and its contextually appropriate target because the former requires de novo activation of a new meaning for the ambiguity while the latter can draw on the previously established sentence context.

This interpretation of the present results is consistent with one tenet of the multiple access model of ambiguity resolution: it takes some time to process an ambiguous word. It is inconsistent with the tenet that one stage of such processing involves the simultaneous activation of both senses of the ambiguity. Rather, it suggests that there is an early stage of ambiguity resolution in which the ambiguity can be reinterpreted due to the additional context provided by a subsequent word. At some later time, a final interpretation has been found and the ambiguous word is immune to further context effects.

\section{General Discussion}

We believe that the backward priming interpretation of the ERP data obtained in
Experiment 2 is also compatible with the naming latency data reported for Experiment 1 . A direct comparison between the behavioral reaction time and ERP onset latencies is not feasible between these were obtained from different subjects. However, it is important to note that the first ERP indication of a differentiation between contextually inappropriate and unrelated targets in one group of subjects precedes the behavioral response of the other group of subjects. Naming latencies hovered around $600 \mathrm{~ms}$ in the short SOA condition of Experiment 1 (see Table 2). At this point in time, mutual priming between ambiguities and their contextually inappropriate targets may already have taken place so that the reaction time to such targets would reflect this benefit.

This backward, or mutual, priming interpretation of RT data which appear to reflect multiple access is supported by evidence obtained from a new reaction time technique which Glucksberg and his col- 
leagues have recently applied to the problem of ambiguity resolution. These investigators have used a variant of the lexical decision task in which RT for nonwords rather than words is the dependent variable. Nonwords are constructed so as to be reminiscent of true words, such as "piamoe" and "kidnea" from "piano" and "kidney," respectively. In a simple wordpair task, subjects are slower to reject "related" nonwords such as "piamo" or "kidnea" following "organ" than "unrelated" nonword controls such as "moepia" or "nedika." This interference is, however, asymmetric. "Organ" influences reaction time for "piamoe," but the presentation of "piamoe" neither facilitates nor inhibits the lexical decision to "organ" (Gildea, 1984). The unidirectional nature of this interference effect was used to construct a lexical ambiguity paradigm which was insensitive to backward priming effects. Reaction time interference was found for only the contextually "related" nonword targets following ambiguous words in a biasing context (Glucksberg. Kreuz, \& Rho, 1986).

Glucksberg's nonword version of the lexical decision paradigm appears to eliminate the possibility of backward priming even at short prime-target SOAs. Since only real word targets were used in the experiments reported here backward priming was not eliminated. Instead we relied on the temporal resolution of the event-related potential measure to distinguish forward from backward priming by their different time courses. The study of this sort of backward (mutual) priming may, in the long run, reveal much about the nature and temporal characteristics of the integration of single word meanings into discourse.

\section{APPENDIX 1}

\begin{tabular}{lll} 
Homograph & $\begin{array}{l}\text { Contextually } \\
\text { appropriate } \\
\text { target }\end{array}$ & $\begin{array}{l}\text { Contextually } \\
\text { inappropriate } \\
\text { target }\end{array}$ \\
\hline $\begin{array}{l}\text { bail } \\
\text { bank }\end{array}$ & $\begin{array}{l}\text { bucket } \\
\text { river }\end{array}$ & $\begin{array}{l}\text { money } \\
\text { account }\end{array}$
\end{tabular}

APPENDIX 1-Continued

\begin{tabular}{|c|c|c|}
\hline Homograph & $\begin{array}{l}\text { Contextually } \\
\text { appropriate } \\
\text { target }\end{array}$ & $\begin{array}{l}\text { Contextually } \\
\text { inappropriate } \\
\text { target }\end{array}$ \\
\hline bats & vampire & baseball \\
\hline bear & carry & grizzly \\
\hline bill & beak & pay \\
\hline bit & chew & piece \\
\hline blues & rhythm & sky \\
\hline bluff & cliff & fake \\
\hline bow & stern & kneel \\
\hline bowl & ball & soup \\
\hline box & fight & cardboard \\
\hline bridge & cards & river \\
\hline bug & spy & insect \\
\hline cabinet & president & cupboard \\
\hline calf & leg & cow \\
\hline can & tin & can't \\
\hline capital & money & washington \\
\hline change & alter & dollar \\
\hline check & over & cash \\
\hline chest & box & body \\
\hline china & japan & dishes \\
\hline club & group & hit \\
\hline coach & carriage & football \\
\hline coast & beach & roll \\
\hline count & duke & ten \\
\hline court & tennis & law \\
\hline date & girl & day \\
\hline deck & cards & ship \\
\hline deed & title & act \\
\hline draft & tap & army \\
\hline draw & tie & sketch \\
\hline fall & winter & down \\
\hline fan & follower & cool \\
\hline tence & sword & wall \\
\hline file & nail & folder \\
\hline $\operatorname{gin}$ & rummy & vodka \\
\hline glasses & drinks & lenses \\
\hline grate & grill & cheese \\
\hline ground & grind & floor \\
\hline hide & skin & seek \\
\hline key & note & lock \\
\hline leaves & goes & trees \\
\hline litter & kittens & trash \\
\hline lot & acre & plenty \\
\hline march & april & walk \\
\hline match & same & light \\
\hline may & june & might \\
\hline means & thinks & average \\
\hline miss & hit & $\mathrm{mrs}$ \\
\hline nag & horse & bitch \\
\hline nails & fingers & hammer \\
\hline nut & bolt & seed \\
\hline organ & liver & piano \\
\hline palm & tree & hand \\
\hline park & car & bench \\
\hline
\end{tabular}


APPENDIX $1-$ Continued

\begin{tabular}{|c|c|c|}
\hline Homograph & $\begin{array}{l}\text { Contextually } \\
\text { appropriate } \\
\text { target }\end{array}$ & $\begin{array}{l}\text { Contextually } \\
\text { inappropriate } \\
\text { target }\end{array}$ \\
\hline pass & mountain & fail \\
\hline pen & pig & ink \\
\hline pick & shovel & choose \\
\hline pipe & smoke & water \\
\hline pit & hole & peach \\
\hline pitch & tonc & throw \\
\hline pitcher & beer & baseball \\
\hline plant & factory & green \\
\hline play & stage & game \\
\hline plot & land & story \\
\hline poker & fireplace & cards \\
\hline pool & table & swim \\
\hline port & wine & harbor \\
\hline pot & soup & marijuana \\
\hline pound & weigh & beat \\
\hline present & give & future \\
\hline press & news & push \\
\hline punch & fruit & hit \\
\hline pupils & eyes & students \\
\hline race & color & run \\
\hline refrain & chorus & stop \\
\hline rest & remainder & sleep \\
\hline ring & bell & finger \\
\hline rose & stood & flower \\
\hline row & line & paddle \\
\hline ruler & measure & king \\
\hline rung & rang & ladder \\
\hline saw & $\mathrm{ax}$ & look \\
\hline scales & fish & weigh \\
\hline second & minute & third \\
\hline sentence & prison & paragraph \\
\hline shed & tool & fur \\
\hline $\sin k$ & swim & kitchen \\
\hline slip & dress & slide \\
\hline slugs & worms & hits \\
\hline solution & mixture & problem \\
\hline spade & ace & shovel \\
\hline spoke & wheel & talked \\
\hline spring & jump & summer \\
\hline squash & racquet & vegetable \\
\hline stall & delay & barn \\
\hline star & movie & planet \\
\hline sticks & stay & stones \\
\hline stock & cattle & exchange \\
\hline story & floor & read \\
\hline straw & hay & $\operatorname{sip}$ \\
\hline swallow & bird & drink \\
\hline table & figure & chair \\
\hline $\tan k$ & gas & guns \\
\hline temples & head & jewish \\
\hline tick & flea & tock \\
\hline tie & win & knot \\
\hline till & soil & cash \\
\hline
\end{tabular}

APPENDIX 1-Continued

\begin{tabular}{|c|c|c|}
\hline Homograph & $\begin{array}{l}\text { Contextually } \\
\text { appropriate } \\
\text { target }\end{array}$ & $\begin{array}{l}\text { Contextually } \\
\text { inappropriate } \\
\text { target }\end{array}$ \\
\hline $\begin{array}{l}\text { tip } \\
\text { tire } \\
\text { toast } \\
\text { toll } \\
\text { top } \\
\text { train } \\
\text { volume } \\
\text { wake } \\
\text { watch } \\
\text { will } \\
\text { yard }\end{array}$ & $\begin{array}{l}\text { turn } \\
\text { sleep } \\
\text { drink } \\
\text { chime } \\
\text { spin } \\
\text { practice } \\
\text { book } \\
\text { wave } \\
\text { look } \\
\text { testament } \\
\text { inches } \\
\text { Unrelated targets }\end{array}$ & $\begin{array}{l}\text { waiter } \\
\text { car } \\
\text { bread } \\
\text { fee } \\
\text { bottom } \\
\text { freight } \\
\text { sound } \\
\text { sleep } \\
\text { wrist } \\
\text { won't } \\
\text { front }\end{array}$ \\
\hline $\begin{array}{l}\text { amount } \\
\text { chain } \\
\text { doll } \\
\text { glad } \\
\text { held } \\
\text { keep } \\
\text { modern } \\
\text { parent } \\
\text { poetry } \\
\text { risk } \\
\text { score } \\
\text { showil } \\
\text { steam } \\
\text { understood }\end{array}$ & $\begin{array}{l}\text { art } \\
\text { classic } \\
\text { echo } \\
\text { glum } \\
\text { honor } \\
\text { lips } \\
\text { nature } \\
\text { pie } \\
\text { proof } \\
\text { scare } \\
\text { sell } \\
\text { sinile } \\
\text { threat }\end{array}$ & $\begin{array}{l}\text { call } \\
\text { curly } \\
\text { final } \\
\text { guru } \\
\text { hope } \\
\text { mineral } \\
\text { never } \\
\text { pill } \\
\text { quotes } \\
\text { school } \\
\text { shine } \\
\text { soon } \\
\text { trigger }\end{array}$ \\
\hline
\end{tabular}

Note. The same 40 unrelated targets used for each of the three stimulus lists.

\section{APPENDIX 2}

\section{Low Associative Context Fillers and Related Target Words}

$\mathrm{He}$ almost got lost driving home because it was so foggy. clear

The interview went well and he gat the job. work

It was a dark and stormy night. day

He admitted that he was wrong. right

He thought the most important issue in the election was peace. war

She was afraid to walk alone after dark. light 
The library kept very short hours and seemed to usually be closed.

open

He glanced out the window and saw that it was a beautiful day outside.

inside

She wanted to find the owner of the dog she had found.

lost

They stayed home and watched an old movie on TV. radio

She had lost her comb.

hair

The professor gave a surprise quiz.

test

She didn't want to travel in Mexico until she had learned Spanish.

language

The scientist had proven the old theory to be false. wrue

They told him the check was in the mail.

letter

He was planning on winning the lottery and becoming rich.

poor

He had never learned to swim and tried to stay where the water was shallow.

deep

She made a point of arriving early.

late

The sun didn't set until ten in the evening. morning

He wrote a note to himself so that he wouldn't forget. remember

He left yesterday.

today

He got paid twice a month.

week

The geese were flying south.

north

He painted his kitchen white.

black

He lifted weights but still thought he was weak. strong

Most truck drivers belong to the Teamsters.

union

He had made many political enemies.

friends
His speech lasted only ten minutes.

hours

She let the phone ring six times but there was no answer.

question

He had trouble eating and sleeping when he was under pressure.

stress

The mountain is twelve thousand feet high.

low

She had always wanted to sail to Hawaii.

island

He was sorry to hear that the old man was dying. dead

His uncle wanted to know why he hadn't settled down and gotten married.

single

He didn't believe that his friend would have told him a lie.

truth

She had moved to New York.

city

The shepherd led his flock to the summer pasture.

field

The man looked very familiar but she couldn't remember his name.

face

The convict tried to get a special pardon from the governor.

state

You could tell by his accent that he had grown up in the east.

west

He wouldn't show his work to anyone until it was finished.

start

The little boy promised Santa Claus that he had been good.

bad

She bought a stuffed toy for her granddaughter. grandson

$\mathrm{He}$ is always careful to wear his seat belt. buckle

He took four aspirin.

headache

She was teaching her dog to beg.

plead

He thought the cake was too sweet.

sour 
He wanted a roommate who would be quiet and neat. sloppy

The first thing she reads in the Sunday paper is the comics.

cartoons

The airline had lost her suitcase.

luggage

Every muscle in his body ached.

sore

They made camp just before sunset.

sunrise

He had forgotten the words to the song.

tune

They went to the zoo to watch the apes.

monkey

She never paid any attention to the gossip.

rumor

The kids had a great time at the circus

clown

The usher was collecting tickets at the entrance.

exit

He bought a quart of milk and a dozen eggs.

bacon

He was wearing a down jacket and mittens.

gloves

They wouldn't let her into the restaurant because she wasn't wearing shoes.

socks

He ordered french fries with his hamburger.

hotdog

She spent many years with an Indian tribe and wrote down many of their stories and legends.

myths

He bought a spool of thread and some needles.

pins

She was afraid of spiders.

web

The medical students had to memorize all of the major arteries.

veins

He got drenched walking in the rain.

umbrella

They couldn't agree on what kind of ice cream to buy and finally settled on vanilla.

chocolate

The sweater was knitted from blue and grey wool. lamb
He refused to clean the kitchen because it wasn't masculine.

feminine

He woke up screaming from a bad dream. nightmare

Everything she owned was in a brown paper bag. sack

The hunter dropped his rifle.

shotgun

Her car broke down in the desert and she had to hitchhike.

thumb

They were out of dish soap. suds

They had a big family dinner every Thanksgiving. turkey

When he cleaned his desk he threw most of his old notes into the trash.

garbage

\section{REFERENCES}

Bentin, S., McCarthy, G., \& Wood, C. C. (1985) Event-related potentials associated with semantic priming. Electroencephalography and Clinical Neurophysiology, 60, 343-355.

BESSON, M., \& MACAR, F. (in press). An event-related potential analysis of incongruity in music and other non-linguistic contexts. Psychophysiology.

Cairns, H. S., \& Kamerman, J. (1975). Lexical in formation processing during sentence processing. Journal of Verbal Learning and Verbal Behavior, 14, 170-179.

CAIRNS. II. S., \& Hsu, J. R. (1980). Effects of prior context upon lexical access during sentence comprehension: A replication and reinterpretation. Journal of Psycholinguistic Research, 9, 1-8.

CARROLl, M., \& KiRSNER, K. (1982). Journal of Verbal Learning and Verbal Behavior, 21, 55-69.

CONRAD, C. (1974). Context effects in sentence comprehension: A study of the subjective lexicon. Memory \& Cognition, 2, 130-138.

Dannenbring, G. L., \& Briand, K. (1982). Semantic priming and the word repetition effect in a lexical decision task. Canadian Journal of Psychology, 36, 435-444.

FISCHLER, I. (1977a). Associative facilitation without expectancy in a lexical decision task. Journal of Experimental Psychology: Human Perception and Performance, 3, 18-26.

FisCHLER, I. (1977b). Semantic facilitation without association in a lexical decision task. Memory \& Cognition, 5, 335-339.

Fischler, I., \& Bloom, P. A. (1979). Automatic and 
attentional processes in the effects of sentence contexts on word recognition. Journal of Verbal Learning and Verbal Behavior, 18, 1-20.

Fischler, I., Bloom, P. A., Childers, D. G., ArROYO, A. A., \& PERRY, N. W. (1984). Brain potentials during sentence verification: Late negativity and long-term memory strength. Neuropsychologia, 22, 559-568.

Fischler, I., Bloom, P. A., Childers, D. G., Roucos, S. E., \& Perry, N. W. (1983). Brain potentials related to stages of sentence verification. Psychophysiology, 20, 400-409.

Foss, D. J. (1970). Some effects of ambiguity upon sentence comprehension. Journal of Verbal Learning and Verbal Behavior, 9, 699-706.

Foss, D. J. (1982). A discourse on semantic priming. Cognitive Psychology, 14, 590-607.

Foss, D. J., \& JEnkins, C. M. (1973). Some effects of context on the comprehension of ambiguous sentences. Journal of Verbal Learning and Verbal Behavior, 12, 577-589.

Geis, M. F., \& WinOgrad, E. (1974). Norms of semantic encoding variability for fifty homographs. Bulletin of the Psychonomic Society, 3, 429-431.

GILDEA, P. (1984). On resolving lexical ambiguity: Can context constrain lexical access? Unpublished doctoral dissertation, Princeton, NJ.

Glucksberg, S., Kreuz, R. J., \& Rho, S. (1986). Context can constrain lexical access: Implications for models of language comprehension. Journal of Experimental Psychology: Learning, Memory and Cognition, 12, 323-335

Gorfein, D. S.. Viviani, J. M., \& Leddo, J. (1982). Norms as a tool for the study of homography. Memory \& Cognition, 10, 503-509.

Grozinger, B., Kornhuber, H. H., Kriebel, J., Szirtes, J., \& Westphal. K. T. P. (1980). The Bereitschaftspotential preceding the act of speaking: Also an analysis of artifacts. In H. H. Kornhuber, \& L. Deecke (Eds.), Motivation, motor and sensory processes of the brain. Electrical potentials, behavior, and clinical use: progress in brain research (Vol. 54, pp. 798-804). Amsterdam: Elsevier.

Harbin, T. J., Marsh, G. R., \& HaRveY, M. T. (1984). Differences in the late components of the event-related potential due to age and to semantic and non-semantic tasks. Electroencephalography and Clinical Neurophysiology, 59, 489-496.

Holcomb, P. J. (in press). ERP correlates of semantic facilitation. Electroencephalography and Clinical Neurophysiology Supplement.

Holcomв, P. J. (1985). Unimodal and multimodal models of lexical memory: An ERP analysis. Psychophysiology, 22, 576. [Abstract]

Kausler. D. H.. \& Kollasch, S. F. (1970). Word associations to homographs. Journal of Verbal Learning and Verbal Behavior, 9, 444-449.
KePPEL, G. (1973). Design and analysis, A researcher's handbook. Englewood Cliffs, NJ: Prentice-Hall.

KEPPEL, G. (1982). Design and analysis, $A$ researcher's handbook (2nd ed.). Englewood Cliffs, NJ: Prentice-Hall.

Kiger, J. I., \& GLASS, A. L. (1983). The facilitation of lexical decisions by a prime occurring after the target. Memory \& Cognition, 11, 356-365.

Kintsch, W., \& Mross, E. F, (1985). Context effects in word identification. Journal of Memory and Language, 24, 336-349.

KorIaT, A. (1981). Semantic facilitation lexical decisions as a function of prime-target association. Memory \& Cognition, 9, 587-598.

Kucera, H., \& Francis, W. N. (1967). Computational analysis of present-day American English. Providence, RI: Rrown IJniv. Press.

KuTAS, M. (1985). ERP comparisons of the effects of single word and sentence contexts on word processing. Psychophysiologv, 22, 575-576. ГAbstract]

Kutas, M.. \& HillyaRd, S. A. (1980a). Event-related brain potentials to semantically inappropriate and surprisingly large words. Biological Psychology, 11, 99-116.

Kutas, M., \& Hillyard, S. A. (1980b). Reading senseless sentences: Brain potentials reflect semantic incongruity. Science, 207, 203-205.

Kutas, M., \& Hillyard, S. A. (1980c). Reading between the lines: Event-related brain potentials during natural sentence processing. Brain and Language, 11, 354-373.

Kutas, M., \& HillyaRD, S. A. (1983). Event-related brain potentials to grammatical errors and semantic anomalies. Memory \& Cognition, 11, $539-550$.

Kutas, M., \& HillyaRd, S. A. (1984). Brain potentials during reading reflect word expectancy and semantic association. Nature (London) 307, $161-163$.

Kutas, M., Neville, H. J., \& HolcomB, P. J. (in press). A preliminary comparison of the N400 response to semantic anomalies during reading, listening, and signing. Electroencephalography and Clinical Neurophysiology Supplement.

Kutas, M., \& Van Petten, C. (in press). Event-related brain potential studies of language. In P. K. Ackles, J. R. Jennings, \& M. G. H. Coles (Eds.), Advances in Psychophysiology (Vol. 3). Greenwich, CN: JAI Press.

McCallum, W. C., Farmer, S. F., \& PoCock, P. V. (1984). The effects of physical and semantic incongruities on auditory event-related potentials. Electroencephalography and Clinical Neurophysiology, 59, 477-488.

Mehler, J., Segui, J., \& Carey, P. (1978). Tails of 
words: Monitoring ambiguity. Journal of Verbal Learning and Verbal Behavior, 17, 29-35.

Meyer, D. E., \& SchVANEVeldt, R. W. (1971). Facilitation in recognizing pairs of words: Evidence of a dependence between retrieval operations. Journal of Experimental Psychology, 90, 227243.

NeELy, J. H. (1977). Semantic priming and retrieval from lexical memory: Roles of inhibitionless spreading activation and limited-capacity attention. Journal of Experimental Psychology: General, 106, $226-254$.

Nelson, D. L., McEnvoy, C. L., Walling, J. R., \& WhEELER, J. W. (1980). The University of South Florida homograph norms. Behavior Research Methods and Instrumentation, 12, 16-37.

Neville, H. (1985). Biological constraints on semantic processing: A comparison of spoken and signed languages. Psychophysiology, 22, 576. [Abstract]

Newman, J. E., \& Dell, G. S. (1978). The phonological nature of phoneme monitoring: A critique of some ambiguity studies. Journal of Verbal Learning and Verbal Behavior, 17, 359-374.

Norman, D. A., \& Bobrow, D. G. (1975). On datalimited and resource-limited processes. Cognitive Psychology, 7, 44-64.

ODEN, G. L., \& SPIRA, J. L. (1983). Influence of context on the activation and selection of ambiguous word senses. Quarterly Journal of Experimental Psychology, 35A, 51-64.

ONIFER, W., \& SwINNEY, D. A. (1981). Accessing lexical ambiguities during sentence comprehension: Effects of frequency of meaning and contextual bias. Memory \& Cognition, 9, 225-236.

Perfetti, C. A., Lindsey, R., \& Garson, B. (1971). Association and uncertainty: Norms of assoriation to ambiguous words. Learning Research and Development Center, University of Pittsburgh.

Picton, T. W., \& Stuss, D. T. (1984). Event-related potentials in the study of speech and language: A critical review. In D. N. Caplan, A. R. Lecours, \& A. M. Smith (Eds.), Biological perspectives on language (pp 303-360). Cambridge: MIT Press.

Rohrbaugh, J. W., \& Gaillard, A. W. K. (1983). Sensory and motor aspects of the contingent negative variation. In A. W. K. Gaillard \& W. Ritter (Eds.), Tutorials in ERP research: Endogenous components. Amsterdam: North-Holland.

RugG, M. D. (1985). The effects of semantic priming and word repetition on event-related potentials. Psychophysiology, 22, 642-647.

SeidenberG, M. S., Tanenhaus, M. K., Leiman, J. M., \& Bienkowski, M. (1982). Automatic access of the meanings of ambiguous words in context: Some limitations of knowledge-based processing. Cognitive Psychology, 14, 489-537.

SeidenberG, M. S.. Waters, G. S., SANDERS, M.. \& LANGER. P. L. (1984). Pre- and postlexical loci of contextual effects on word recognition. Memory \& Cognition, 12, 315-328.

Simpson, G. B. (1981). Meaning dominance and semantic context in the processing of lexical ambiguity. Journal of Verbal Learning and Verbal Behavior, 20, 120-136.

SIMPSON, G. (1984). Lexical ambiguity and its role in models of word recognition. Psychological Butletin, 96, 316-340.

SWINNEY, D. A. (1979). Lexical access during sentence comprehension: (Re)Consideration of context effects. Journal of Verbal Learning and Verbal Behavior, 18, 645-659.

SwinNey, D. A., \& Hakes, D. A. (1976). Effect of prior context upon lexical access during sentence comprehension. Journal of Verbal Learning and Verbal Behavior, 15, 681-689.

Van Petten, C., \& Kutas, M. (1985). An electrophysiological study of ambignity. Psychophysiology, 22, 618. [Abstract]

(Received July 21, 1986)

(Revision received November 24,1986 ) 